Technological University Dublin

DƯBLIN

ARROW@TU Dublin

2013-05-31

\title{
Lone Parents, Leisure Mobilities and the Everyday
}

Bernadette Quinn

Technological University Dublin, bernadette.quinn@tudublin.ie

Follow this and additional works at: https://arrow.tudublin.ie/tfschhmtbook

Part of the Human Geography Commons, and the Leisure Studies Commons

\section{Recommended Citation}

Quinn, B. (2013) Lone parents, leisure mobilities and the everyday, in, Linehan, D. and Crowley, C. (Eds), Spacing Ireland: Space, Culture \& Society in a Post-Boom Era. Manchester: Manchester University Press, pp. 89-101. (ISBN: 9780719086733 )

This Book Chapter is brought to you for free and open access by the School of Tourism \& Hospitality Management at ARROW@TU Dublin. It has been accepted for inclusion in Books / Book chapters by an authorized administrator of ARROW@TU Dublin. For more information, please contact arrow.admin@tudublin.ie, aisling.coyne@tudublin.ie,gerard.connolly@tudublin.ie.

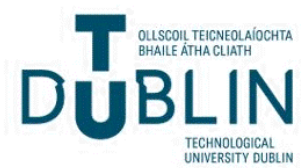




\title{
Lone parents, leisure mobilities and the everyday
}

Citation: Quinn, B. (2013) Lone parents, leisure mobilities and the everyday, in, Linehan, D. and Crowley, C. (Eds), Spacing Ireland: Space, Culture \& Society in a Post-Boom Era. Manchester: Manchester University Press, pp. 89-101. (ISBN: 9780719086733 )

\begin{abstract}
This chapter highlights the importance of the ordinary as a site for enquiring into how people make sense of their worlds. The primary intention is to highlight the spatiality of everyday leisure practices and to unravel some of the connections that link these to the occasional leisure practice of holidaying. Empirically, the study focuses on a group of female lone parents of dependent children living on low incomes in Dublin. In Ireland as elsewhere, lone parent families constitute a sizeable, growing but marginal societal group. For the women studied, leisure constituted informal, unstructured and modest activities that were stitched into daily routines and mobilities in a variety of unremarkable ways. Of note is the extent to which distinctions between work and leisure and between obligation and leisure were blurred. Overwhelmingly clear was the fact that even the most modest engagement in leisure activities facilitated social engagement and served as very important sustaining and coping mechanisms. Time and financial factors clearly constrained the women's ability to practise leisure activities, however, so too did other factors including the quality of everyday spaces, a very prevalent ethic of care, social perceptions of lone parents, the social constructedness of public and certain private spaces, and the workings of the institutionalised tourism industry. There is much in the data to suggest that the myriad cultural practices, habits, mobilities and ways of being that make up our everyday existence are far more connected into, and mutually constitutive of, our extra-ordinary endeavours than might be popularly thought.
\end{abstract}

Keywords: Lone parents, women, leisure, coping, constraints, social exclusion, Dublin, Ireland 


\section{Introduction}

Recent social and economic commentary on Ireland has tended to accentuate the extreme changes associated with the 'Celtic Tiger' era. Stories of ostentatious consumption patterns dominated discursive narratives in popular, academic and policy fora. This was for good reason, as trend data of all descriptions attested to startling transformations in people's lifestyles and mobilities. To take just one example: CSO data (2007, 2008) show that foreign overnight trips taken by Irish residents increased by a staggering $113.8 \%$ over the period 2000 to 2008 , rising from 3.76 to 8.04 million trips. In the aftermath of the boom, the rate of Irish trip-taking overseas has begun to decrease: by $10.5 \%$ between $2008-2009$ and $6.8 \%$ between $2009-2010$. Everywhere now, there is contraction of activities and mobilities, and a sense of a return to basics, as businesses, households and individuals alike variously re-adjust priorities, reduce discretionary consumption or struggle to survive. Social and economic commentary remains equally striking in its highlighting of extremes, but now it is mind-boggling debt problems, sharp rises in unemployment and emigration, and dramatic downturns in consumer confidence that predominate. Omnipresent in these very recent commentaries and debates is the gritty and often harsh material lived realities of daily life in everyday places. Irish society is being re-grounded, as the ordinary and the everyday come back into focus.

This chapter picks up on this return to basics. It highlights the importance of the ordinary as a site for enquiring into how people make sense of their world through the routine trajectories that they make and re-make through everyday spaces, and through the jumble of cultural forms and practices that make up their everyday life (Katz 2004). The focus is on leisure practices and mobilities. To date, the conceptualisation of leisure in the social sciences has tended to be framed by notions of time rather than space (Kay 1998. Henderson and Hickerson 2007) and while interest in spatial issues has increased since the late 1990s (Aitchison 1999), the spatiality of leisure continues to offer much scope for further theorisation. 'Of all the leisure spaces available to the majority of the population, it is the home that has become increasingly significant in everyday lives' 
(Dart 2006 p.314). Despite this, the paradox noted by Glyptis (1987) still holds largely true: whilst home is the place where most leisure time is spent, it remains underresearched. The research reported here builds on Quinn (2010), where the spatiality of leisure in the ordinary, everyday spaces in and around the home was explored in an Irish urban context. The primary intention here is to highlight the spatiality of everyday leisure practices and to unravel some of the connections that link these to the occasional leisure practice of holidaying. Empirically, the study seeks to develop insights into the lived realities of a particular group of women: lone parents of dependent children living on low incomes in Dublin. To frame the study, the chapter draws on theoretical ideas about leisure and the everyday.

\section{Leisure and the everyday}

As Larsen (2008) points out, much theorising about the occasional leisure practice of holidaying has been historically premised on opposing dualisms, the most fundamental of which is the understanding that tourism's raison d'être lies in its opposition to practices of the everyday. To go away on holiday was to escape from the mundane realities of the everyday. Cohen (1979 p. 181), for example, in a seminal contribution to the literature referred to holidays as 'a no-work, no-care, no-thrift situation'. In consequence, the activities and practices of the everyday have tended to be studied in isolation from those of the extra-ordinary. This has even been the case within the specific domain of leisure activities, where as Bey and Lehto (2007 p. 2) point out, few empirical evidences as to the relationship between an individual's daily recreation activities and what he or she, as a tourist, chooses to do at a destination' exist. For a variety of reasons, the shortcomings of this dichotomous way of thinking are now becoming increasingly clear. Most obviously, alertness to 'time-space compression' (Harvey 1989: 240), to the globalised nature of contemporary society and to the 'stretching out' of social networks that this entails (Urry 2000) has been pivotal. Increasingly now, it is understood that tourism can 'involve connections with, rather than escape from, social relations and the multiple obligations of everyday social life' (Larsen et al 2006 p.45). It is argued that the relevance of researching the leisure domain has increased, and researchers like Larsen (2008) have drawn on Lefebvre's 3 
(1991) belief that no practice escapes everydayness to argue that the social practice of holidaying is strongly conditioned by routine. Advocates of what is referred to as the 'performance turn' in tourism theory have begun to explore these interconnections, arguing that 'although suffused with notions of escape from normativity, tourists carry quotidian habits and responses with them: they are part of their baggage (Edensor 2001 p.61). Larsen (2008 p.22), for example, argues that occasional leisure, in the form of holidaying, is informed by 'everyday performances, social obligations and significant others'. Researchers like these argue that it is through understanding the everyday, ordinary practices that tourists undertake in the process of 'doing' tourism that we can come to a fuller knowledge of how tourism is implicated in reproducing social relations.

The need to re-think the link between the ordinary and the extra-ordinary in the leisure domain has also been prompted by developments in feminist contributions to both geography and leisure research. Here can be seen a reminder not to overlook the significance of the apparently mundane spatialities of ordinary places in the rush to investigate the exciting new mobilities and practices that make manifest the 'stretching out' of social relations. Within geography, feminist researchers have paid most heed to the everyday. As Dyck (2005 p.234) wrote 'we need close attention to the spaces of the everyday to keep women visible in rapidly changing world conditions, where their activities tend to slip into the shadows of dominant models in the literature'. Feminist geographers have also made it clear that enquiries into 'the routine, taken-forgranted activity of everyday life in homes, neighbourhoods and communities'... can 'help us see how the 'local' is structured by wider processes and relations of power' (Dyck 2005 p.234). Specifically within leisure studies, the problem with separating out the ordinary from the extra-ordinary mirrors the problematic dichotomy that historically characterised thinking about the work-leisure relationship. Traditional definitions of leisure as 'non-work' ill-considered the fact that many people are not engaged in paid work outside the home and that for many women, especially mothers, the notion of describing the private domestic zone as a 'non-work' environment is seriously misguided (Allen 1993). It is now well established that notions of home as 'natural' havens of recreation are partial, gendered interpretations that fail to consider how space is socially constructed. 


\section{Lone parents in Ireland}

In 1990, Winchester asserted that one parent families constituted one of the most rapidly growing types of household in the developed world. The case of Ireland bears out this assertion. The number of lone parent families rose sharply in the 1980s and 1990s (Fahey and Russell 2002) and more than doubled in the twenty year period 1986 - 2006 (Lunn et al. 2010). Research has consistently found that lone parents are more likely to be from lower social classes than other parents (Lunn et al 2010). According to EU SILC data (CSO 2009), they experience the highest at risk of poverty (35.5\%), deprivation (63\%), and consistent poverty (17\%) rates of any household type.

In 2006, 91\% of the approximately 120,000 lone parents in Ireland were female (Lunn et al 2010). A predominance of females as lone parents is also found elsewhere in Europe (EU Commission 2007, Solomon and Titheridge 2008). EU SILC trend data suggest that the fortunes of lone parent families in Ireland improved over the boom years: in 2004, $31.1 \%$ were living in consistent poverty compared to $17 \%$ in 2009 . Nevertheless, lone parent families continue to stand out as a societal group clearly exposed to poverty. Their prospects in the face of current economic difficulties are unclear.

The research reported here is based on data gathered in 2006 and 2009 and relates to fifteen female lone parents living on low incomes in inner and suburban Dublin city. All of them were White women from Dublin, except for one who was Nigerian. They parented between 1 and 4 dependent children and were aged between late-20s and mid-50s. Small-scale focus groups and in-depth individual structured conversations were used because they offer 'a perspective on women's experiences in a way that more structured methods of research cannot' (Miller and Brown 2005 p.408). The study examines how leisure 'fits' into the everyday and occasional lifestyles of these women.

\section{Daily mobilities and practising leisure at home}


In spatial terms, the routine mobilities of the women studied had a lot in common, with most being both limited and highly routinised. Three of the women lived with their parent(s), and for them, the main trips were home-work-school-shops/services. For the others (with the exception of the Nigerian woman), these trips were supplemented by very frequent, in many cases daily, trips to the homes of extended family members and to other places significant in the wider family context (e.g. a family grave, a granny's nursing home). All of the women lived relatively close to where they worked, and indeed, most currently lived in or close to the area where they had grown up. None of this is at all surprising. Feminist geography has shown that the space-time fixity constraints that bind women to specific places are stronger than those associated with men (Schwanen et al 2008, Kwan 2000) and that 'care-giving and housework punctuates and fragments (womens') time-space paths' (Schwanen et al. 2008: 2111). It seemed that most of the daily trip-taking was associated with caring obligations, e.g. helping out an elderly parent or taking a nephew to school. While Solomon and Titheridge (2008) suggest that lone-parents in the UK are the least likely of any household type to have private transport, somewhat surprisingly here, several of the women, even those within the inner city, owned and regularly used cars. This perhaps points both to the limitations of the city's public transport system and to gains made by this low income group during the Celtic Tiger years.

The scale of obligation combined with the nature of the home environment meant that there was little time for women to self-determine ways of being at home. Particularly for those women who did not live with their parents, relaxation was rare. Typical responses when asked about 'time to themselves' were 'no time', 'no never', 'nothing, only when I go to work'. Furthermore, indicating the strong ethic of care that prevailed, this was widely accepted as 'how things were'. As Susan said: 'not to have much time to yourself as a mother is natural. You have to step up to the mark. Have to make sure you do your best for your child'.

If these women lacked time, space was also an issue. While some were happy with the quality of their living environs this was not the case for all. For Hilary, the lack of time was 
strongly compounded by the quality of the spatial capital available to her. As she explained: 'my child is permanently with me, don't even get 5 minutes away from her. We don't even lock the bathroom door. We live on the $6^{\text {th }}$ floor of an apartment block and every door in the house is permanently left open because I'm terrified she' $d$ fall out the window.' Hilary articulated how she felt her difficult spatial environs to be impacting upon her: I've had desperate trouble at home because I'm living on my own. To live in big blocks of flats you have to be tough. I am quite soft but I have no problem knocking somebody's $f^{* *}$ king block off. It's the environment I'm in, it's like adapting to your environment, it's the way you have to survive'. The problematic quality of the private and public space in the home environs was a recurring theme, especially with respect to the surrounding public space, when the women expressed concerns about their children's welfare. For women like Grainne it was a constant constraint on the ability to relax:

'it's terrible, there's nothing for them (the children), they're always getting themselves into trouble, ... if they're out there playing ball, if the ball goes on the tracks, the danger... if they go too far then you're worried where are they, what are they up to. So you've constantly the worry'.

For the three women who lived with a parent(s), things seemed calmer. However, in general, lives were characterised by multi-tasking, juggling, rushing around, thinking for and about several people simultaneously. Thus, relaxation and a focus on the self only happened in certain times and spaces. Most obviously, albeit very modestly, selfdetermined relaxation happened at home, sometimes in the early morning before the daily household obligations began and while the communal spaces of the home were calm, quiet and relatively empty. Mostly, however, relaxation happened in the evening, when tasks were complete and communal spaces had emptied out. Listening to the radio and watching television were the dominant forms of recreation. Several of the women regularly watched soap dramas. Others smoked a cigarette on the balcony, had a beer on the sofa, or read the paper after the children had gone to bed.

\section{Leisure outside of the home}


Activities that required movement outside of the home specifically for leisure-oriented reasons were rare. Only Laura had a weekly formal leisure engagement: she played bingo in the local pub. Regular, informal leisure activity was almost as rare. Susan explained how she walked her dog on the beach twice a week while her daughter attended a dance class. Patricia described how she walked alone to the shop every Saturday morning to get the newspaper, and this for her was leisure. Pamela regularly dropped into her neighbour for tea, while Adele explained that the only physical activity she took was running to catch the bus on her way to and from work. For the three women who lived with a parent, there seemed to be more opportunities to focus on the self. The one woman who went out regularly in the evening (to play bingo in the local pub) was in this category. Another, Kate, lived with her parents during the week but spent every weekend at a friend's house.

Most of the women, however, did not go out regularly. Sarah explained that she had not had a night out in five months because she couldn't afford it. This was a common theme, a lack of finances meant that socialising was a rarity. Space was another factor. As James et al (1998: 39) reminds us, social space is never a merely neutral location. In the discussions about where and how the women relaxed, it was evident that they clearly understood both time and space to be socially constructed. While certain places like the work-place or a neighbour's kitchen provided comfortable and positive spaces for the women to be in, other spaces were alienating. The limited socialising that characterised these women's lives was undoubtedly linked to their understandings of how society perceived them. Patricia expressed this very clearly: 'I feel that if you are not married, when you come back (from living abroad) and you're on your own, people don't want to know you. They don't invite you for drinks, are afraid that you'll take their husband or afraid of this/that. Hilary too spoke about feeling 'easy $f^{* *} k i n g$ prey for other people's partners (if you go to parties), because you're on your own'. Adele could also relate to this: 'But you can't go somewhere on your own, what would you be doing? You're not having fun, people are looking at you'. These findings empirically support Bavinton's (2007) contention that leisure spaces are contested political arenas where power is negotiated, won and lost. 
For the women who worked outside of the home (in part-time positions, or in community employment schemes), the workplace was a vital place for recreation. It constituted an escape from the stresses and burdens of the domestic zone and in line with extant research (Dart 2006) it was a crucial link into sustaining social networks. The blurring of distinctions between work and leisure evident here was replicated to an extent in the practicing of everyday obligations. The women's social worlds were rooted in their extended family networks. Usually, there was obligation involved, but this was often simultaneously dutiful and fun. For example, while a woman might have been babysitting her sister's children, she also may have had a coffee and a chat with her. Similarly, while someone may have had to cook a meal for a parent, she may have also stayed to watch a dvd. This practicing of obligation in conjunction with simple, informal recreation was a very sustaining endeavour.

\section{Holidaying - away from or into the ordinary?}

Out of step with the highly mobile lifestyles that apparently characterised the Celtic Tiger years, most of these women did not holiday regularly. Those who did, tended to do so for particular reasons. Patricia, for example, travelled to visit her grown-up children who live abroad. She is divorced from a non-rish person and travelled regularly to visit family and friends. For her, holidays were replete with mixed emotions, as she physically engaged with her tension-filled, stretched-out familial network. Adele also travelled regularly but again, travelling and holidaying were embedded both in obligation and ordinariness. She regularly travelled to Nigeria to visit family but this was a difficult process: she had to leave her children behind because of cost, and arrange for them to be cared for in her absence; because of her immigrant status, she had to apply for a visa each time she left the state, a costly and burdensome constraint. In both of these cases, holidaying was not so-much 'an escape from' the routine of home but rather a way of 'reaching into' the ordinariness of family lives being lived elsewhere. For other women like Angela and Valerie, an annual family holiday was made possible only because of the intervention of an NGO. While this was welcome, and enjoyable to an extent, the everything obligations of child-care, cooking, cleaning etc. dissipated 
only modestly, while routine concerns about matters like child safety and finances became increasingly fraught because of the new risks posed by unknown seaside environments and the commercialised nature of holiday resorts with their gambling arcades and fairgrounds. Another woman who holidayed regularly was Laura. She went away on the annual weekend domestic breaks organised by the pub where she regularly played bingo. In Laura's availing of this social network can be seen a very obvious continuity between the leisure practices of the everyday and those of the occasional.

Access to disposable income is a prerequisite for formal, structured leisure activities like holidaying. For some of the women, like Linda and Kate, holidaying was virtually an unknown social practice for this reason. They were completely excluded from the marked rise in overseas trip-taking that came to characterise Irish lifestyles during recent decades. Some of the others, were determined to holiday and made supreme efforts to do so. Grainne, for example, paid 10 euro every week for 2 years in order to travel on a group pilgrimage to Lourdes. The occasion was her $40^{\text {th }}$ birthday, and this was her second-ever holiday as an adult. As she explained:

'Yeah, the parish, my friend's mother runs it ... she'd have to come down because if she didn't come down for me to give the 10euro I wouldn't, you know, you'd spend it on something, so she'd be down the day you got paid to make sure you paid it...'

In similar vein, Hilary was planning to spend two days in Galway for a friend's wedding. This was to be her first trip away in two years and she had been saving for the previous eight months. Meanwhile, Susan, determinedly saved regularly to pay for her annual week away. For women like these, a holiday is something that must be budgeted for months in advance. It comes only at the expense of other items and is a very considered investment. The 2009 data showed signs that these holiday savings were coming under increasing pressure from other more essential demands. Yet for several women, it was clear that holidaying is perceived to offer a highly prized and much desired 'escape'. Holidays seem to restore what the routines, experiences and spaces of these women's everyday lives take away: the ability just to 'be' oneself. As Grainne 10 
said of her holiday: 'but it was just, you're just totally at peace, it was fantastic'. While Linda, who rarely went on holidays, explained: 'well I actually got away for an overnight .... I got away for one night and it was great. Just not worrying about the kids and just time to myself, that I have to say, that was, that I could just relax and do what whatever I wanted'. Susan too, 'loves the build up to the holiday'. For her, it meant a break from obligation 'no hanging out a wash, no sweeping floors' and complete ease: she claimed that it is only while away on holidays that she can sleep through the night undisturbed. Even though she acts as primary care-giver to four family members while on holidays, once away from home, tasks seem less onerous. Away from the strictures of her home space she finds it easier to self-determine her workload (e.g. she insists on going out for dinner every evening) and to be at ease. This ability to control her experience is vital in how she performs being on holiday.

\section{Routine and occasional leisure mobilities - common constraints}

The data showed routine mobilities and holidaying mobilities to be similarly constrained. The constraints at issue relate not only to finances but also to a variety of other factors including the obligations associated with a strong care ethic, the lack of practice in self-determining choices, and the contested nature of social spaces. Hilary, for example, was only going to the wedding in Galway because her daughter had also been invited. She knew that her lone parent status limited her holidaying mobility, just as it did her social practices more generally. For others, the ability to holiday was constrained by an inability to shake off their sense of family obligation: Ellen, for example, talked about her fearfulness of going on holiday because of having to leave her children in the care of others. Sometimes in the holiday environment, the sense of obligation transposed into guilt, as in Grainne's case where her struggle to abstract herself from her routine care-giving role was clear: 'Fantastic, absolutely fantastic, it was just a break away, I even said to my family, I said I'm not being bad, you didn't even enter my head there was so much holy things going on. Don't get me wrong, at night time I'd say oh God, I hope my ma was alright today and things like that...' 
The value that many of the women placed on holidaying was accentuated by a general understanding that they were being marginalised and excluded from what had become, during the boom years of the 1990s and 2000s, a widespread social practice in Ireland. In not being able to afford a holiday, they and their children were missing out. The awareness of being marginalised acted to compound the actual marginalisation itself. Women like Rose, Angela and others who could not afford to take a holiday felt this to be a failure on their part as parents, and felt a sense of guilt. Comments like: 'they (their children) should be on the beach, they should be doing happy things, so you're not feeling as bad'; 'To be honest with you it's like, can I have 20 euro to go to the pictures, can I have 10 euro to go swimming, can I have 5 euro to do whatever, everything is just .... money, money. I'm like a bleedin' bank machine when they are holidays .. and then you feel lousy if you haven't got it, you know that way'. 'I couldn't go on a Spanish holiday, I have five of them, you know, here on me own with them, you know what I mean, so I couldn't afford to bring them on a holiday'.

For a few women, the sense that lone parents, as a societal group, were being actively socially marginalised by the institutionalised tourism industry was well understood. Pamela, who was planning to take her first holiday in 'nearly 40 years' later in the year, communicated this very clearly:

'Travel agencies ..., you know the way sometimes you go and they're all 2 adults and 2 children... Yeah, 2 adults and 2 children, that's very discriminating from a one parent family... Don't you think that'd switch you off the family holidays, .... you're saying to yourself: ' $f^{* *} \mathrm{~K}$ it, does that mean I have to find somebody to come with me, you know, to get it, because the fact that it's 2 adults and 2 children'

\section{Conclusions}

Lone parent families constitute a very sizeable, growing but marginal societal group. They are also a very heterogeneous group. The women studied here differed in numerous ways including age, number and age of children, reason for lone parent 12 
status, living arrangements, employment status, skills levels and income. Race was another factor. The pattern of immigration that characterised the Celtic Tiger period has been a force of dynamism within this societal group and while this study included just one immigrant parent, it offers the briefest glimpse into the changing landscape of lone parents and of how the inclusion of immigrant parents introduces new complexities that merit much further enquiry. While the recent economic boom period may have generated some improvements for this group (car ownership and some evidence of overseas holiday-taking are two indicators noted here), statistics show that lone parent families remain particularly vulnerable to poverty. This study found indications that the current economic downturn is likely to increase the financial pressures and stressful living conditions constantly negotiated by lone parents. In such a scenario, leisure engagement is likely to become even less feasible than it already is, and thus its quality of life enhancing potential will also be diminished.

Overall, the findings presented here concur with extant research pointing to the holistic nature of women's lives (Gregory 1982). For the women studied, leisure constituted informal, unstructured and modest activities that were stitched into daily routines and mobilities in a variety of unremarkable ways. Of note is the extent to which distinctions between work and leisure and between obligation and leisure were blurred. Overwhelmingly clear was the fact that even the most modest engagement in leisure activities facilitated social engagement and served as very important sustaining and coping mechanisms. Undoubtedly, the study group faced numerous constraints on their ability to practise leisure activities. Time and financial factors were clearly at play, however, so too were other factors including the quality of everyday spaces, a very prevalent ethic of care, social perceptions of lone parents, the social constructedness of public and certain private spaces, and the workings of the institutional tourism industry. Several of these are well acknowledged in the leisure literature but the critical and varied roles that space plays in shaping leisure outcomes remains underresearched. Here, empirical evidence of these roles appeared in: the poor quality of home spaces; the absence of recreational spaces for these women and their children; the difficulties in negotiating the highly contested nature of certain public spaces and; the vitally sustaining role that safe, comfortable spaces can play in affording leisure 13 
engagement. Further enquiries into the complex nature of these roles and outcomes constitute important avenues for future geographical research.

More broadly, the study offers insights into some of the ways in which routine leisure experiences shape the extra-ordinary practice of holidaying, and vice versa. These micro investigations illustrate the argument that posits the local (ordinary) and the global (extra-ordinary) not in terms of universality and particularity, but rather as mutually constituting sets of practices (Holloway and Valentine 2000). There is much in the data to suggest that the myriad cultural practices, habits, mobilities and ways of being that make up our everyday existence are far more connected into, and mutually constitutive of, our extra-ordinary endeavours than might be popularly thought. In consequence, a key theme running through this chapter is that dichotomous, bounded ways of thinking about place and the ordinary on the one hand, and about space and the extra-ordinary on the other cannot fully capture the complexities of how and why we make sense of our worlds as we do.

Finally, while in this instance, data analysis did not specifically emphasise the emotional insights generated, the data clearly communicated how emphatically the women 'felt' their worlds. Anger, frustration and fear, exhaustion, worry and anxiety, joy, ease and pleasure were all articulated in abundance, attesting to the variety of ways that people come to know, understand places. An important challenge for geographers is to correspondingly conceive of place as multi-dimensional and multi-sensorial so as to make space both for the emotions and for the kinds of knowledges that they expose.

References Boughton, J.M., 2002. The Bretton Woods proposal: an indepth look. Political Science Quarterly, 42(6), pp.564-78.

Silverman, D.F. and Propp, K.K. eds., 1990. The active interview. Beverly Hills, CA: Sage. 
Press. Smith, J., 1975. A source of information. In: W. Jones, ed. 2000. One hundred and one ways to find information abou

Aitchison, C., 1999. New cultural geographies: the spatiality of leisure, gender and sexuality. Leisure Studies, 18(1), pp.19-39.

Allen, J., 1993. Motherhood, the annihilation of women. In: A. M. Jaggar and P. S. Rothenberg, eds. Feminist Frameworks. New York: McGraw-Hill. $3^{\text {rd }}$ edn,

Bavinton, N. 2007. From obstacle to opportunity: leisure and the reinterpretation of constraints. Annals of leisure Research, 10 (3/4), pp.391-412.

Bondi, L., 2005. Making connections and thinking through emotions: between geography and psychotherapy. Transactions, Institute of British Geographers, 30, pp.433-448.

Brey, E. T. \& Leyto, X. Y. 2007.The relationship between daily and vacation activities. Annals of Tourism Research, 34 (1), pp. 160-180.

Central Statistics Office, 2009. Survey on Living Conditions (SILC). Dublin: Stationary Office.

Central Statistics Office, 2007. Tourism Trends. Dublin, CSO.

Central Statistics Office, 2008. Tourism Trends. Dublin, CSO.

Cohen, E., 1979. A phenomenology of tourist experience. Sociology, 13, pp. 179-202.

Dart, J., 2006. Home-based work and leisure spaces: settee or work-station? Leisure Studies, 25 (3), pp. 13-328.

Dyck, I., 2005. Feminist geography, the 'everyday', and local-global relations: hidden spaces of place-making. The Canadian Geographer 49(3), pp. 233-243.

Edensor, T., 2001. Performing tourism, staging tourism - (re)producing tourist space and practice. Tourist Studies 1, pp.59-81. 
European Community, 2007. Study on Poverty and Social Exclusion among Lone Parent Households, Brussels: European Commission.

Fahey T. and Russell, H., 2002. Family Formation in Ireland. Trends, Data Needs and Implications. Dublin: ESRI.

,

Glyptis, S., Mclnnes H. and Patmore, A., 1987. Leisure and the Home. London: The Sports Council.

Henderson, K. A. and Hickerson, B., 2007. Women and leisure. Premises and performances uncovered in an integrative review, Journal of Leisure Research 39 (4), pp.591-610.

Holloway, S. L. and Valentine, G., 2000. Spatiality and the new social studies of childhood. Sociology, 34 (4), pp.763-783.

James, A., Jenks, C. and Prout, A., 1998. Theorising Childhood. Cambridge: Polity Press.

Katz, C., 2004. Growing up Global: Economic Restructuring and Children's Everyday Lives. Minneapolis: University of Minnesota Press.

Kay, T., 1998. Having it all or doing it all? The construction of women's lifestyles in timecrunched households. Leisure and Society, 21 (2), pp. 438-454.

Kwan, M. P., 2000. Gender difference in space-time constraints. Area, 32(2), pp. 145-156.

Larsen, J., 2008. De-exoticising tourist travel: everyday life and sociality on the move. Leisure Studies, 27 (1), pp.21-34.

Larsen, J., Urry, J. and Axhausen, K.W., 2007. Networks and tourism: Mobile social life. Annals of Tourism Research, 34 (1), pp.244-262.

Lefebvre, H. 1991. Critique of Everyday Life London: Verso.

Lunn, P. Fahey, T. and Hannan, C., 2010. Family Figures: Family Dynamics and Family Types in Ireland, 1986-2006. ESRI Survey \& Statistical Report Series 29, Dublin: Family Support Agency and ESRI.

Massey, D., 1991. A global sense of place. Marxism Today, June, pp.25-26. 
Miller Y. D. and Brown, W. J., 2005. Determinants of active leisure for women with young children - an 'ethic of care' prevails. Leisure Sciences 27 (5), pp. 405-420.

Quinn, B., 2010. Care-givers, Leisure and meanings of home: a case study of low income women in Dublin. Gender, Place and Culture, 17 (6), pp.759-774.

Schwanen, T., Kwan, M. P. and Ren, F. 2008. How fixed is fixed? Gendered rigidity of space-time constraints and geographies of everyday activities. Geoforum, 39, pp.21092121.

Solomon, J. and Titheridge, H., 2008. Social exclusion, accessibility and lone parents'. Paper presented at the UK-Ireland Planning Research Conference, Belfast, $18^{\text {th }}-20^{\text {th }}$ March, 2008.

Winchester, H. P. M., 1990.Women and children last: the poverty and marginalization of one-parent families. Transactions, Institute of British Geographers, 15, pp.70-86.

Urry, J., 2000. Sociology Beyond Societies. London: Routledge. 